\title{
The Distributional Asymmetries OF ENGLISH ANTONYMS IN LANGUAGE USE
}

\begin{abstract}
Corpus data evidence shows that antonymous pairs tend to be used in a preferred sequence in a sentence. Jones (2002) proposed seven factors as sequence rules in his study of English antonyms (morphology, positivity, magnitude, chronology, gender, phonology and idiomaticity), presenting as only marginal the factors of word frequency and markedness. This research differs from Jones' study with respect to methodology, the size of the database and the treatment of the concept of markedness, which results in a much higher proportion of statistically relevant pairs, and different conclusions regarding the factors of antonym ordering. It argues that there is a strong correlation between antonym sequence in language use and the concept of markedness. It is argued that the distributional asymmetries of antonym ordering in language use are conceptual in nature and influenced by the principle of markedness and the principles of temporal and visual-spatial ordering.
\end{abstract}

Key words

Antonymy; distributional asymmetry; markedness; language use

\section{Introduction}

In its broadest sense, antonymy covers a wide range of binary contrast pairs which express the opposite of each other, belong to the same word class and share all their crucial semantic properties but one (e.g. male/female, high/low, give/ receive, above/below, success/failure, implicitly/explicitly). Such word pairs are said to be minimally different because they differ in only one relevant criterion (Clark 1970; Hale 1971). In a pragmatic approach to antonymy, which takes into 
account the findings that semantic relations are contextually dependent, the minimal difference implies that the members of a binary contrast set have all the same contextually relevant properties but one (Murphy 2003). The criterion of contextually relevant minimal difference is able to account for the most prototypical examples of the relation of contrast (e.g. dead/alive) as well as the whole range of contrast pairs attested in language use, such as the ones dependent on contextual knowledge (e.g. natural/social when referring to sciences). In its narrow sense, however, antonymy is a semantic relation of binary opposition that holds only between a small number of adjective - adjective pairs with contrary meanings in language (i.e. gradable adjectives such as hot/cold), as opposed to complementaries (true/false, male/female) and other opposites in language, such as top/bottom, come/go, above/below, north/south, and so on (Lyons 1977; Lehrer and Lehrer 1982; Cruse 1986; Justeson and Katz 1991, Justeson and Katz 1992; Murphy and Andrew 1993; Mettinger 1994; Fellbaum 1995). Numerous recent corpus studies on antonym use doubt the necessity to make theoretical distinctions based on gradability, suggesting that all antonymous pairs share core antonym properties and will be recognized as such by any native speaker (Jones 2002; Murphy et al. 2009; Kostić 2011; Lobanova 2012; Kostić 2015a, 2015b, inter alia). By antonyms in this article we mean all pairs of word-concepts (i.e. conceptual representations of words) that differ in only one contextually relevant property and occur in binary semantic contrast in language use. This is in line with the metalexical and pragmatic approach to paradigmatic semantic relations proposed by Murphy (2003), who argues that antonymy is contextually dependent and predictable by means of a single relational principle, reflecting conceptual knowledge about words rather than lexical knowledge of words (Murphy 2000).

The traditional notion about paradigmatic relations is that the words in a paradigmatic relation must be replaceable, one for the other, in all contexts. Although antonymy is one of the paradigmatic relations, members of an antonymous pair may not show symmetrical distribution in actual language use. The motivation for this study is the observation, based on corpus data, that antonymous pairs tend to be used in a preferred sequence in a sentence. For example, of the fiftysix English antonymous pairs investigated by Jones (2002) in a corpus of 3,000 sentences sampled from a 280 million word corpus of British journalistic texts, only fourteen did not show any marked preference towards either of the two possible orderings. In order to explain this observation, Jones proposed seven factors as sequence "rules" (morphology, positivity, magnitude, chronology, gender, phonology and idiomaticity), presenting as only marginal the factors of word frequency and markedness (in the sense of semantic neutrality). Jones also admitted that a handful of antonyms on his list defied explanation and concluded that "rules are there to be broken as well as obeyed" and that often "no clear explanation can be found" for reversing the "normal" sequence (Jones 2002: 136).

This research aims to establish the factors of distributional asymmetries of English antonyms within a sentence in a much larger corpus of 450 million words, starting from a different methodological premise, and taking into account 
a different treatment of the concept of markedness. The analysis is based on examples taken from The Corpus of Contemporary American English $\left(\mathrm{COCA}^{1}\right)$, and includes fifty-six antonymous pairs and a total of 40,202 sentences in which these pairs co-occur. It will be of special interest to explore whether the standard markedness criteria are relevant in antonymic contexts in actual language use and why antonyms tend to be used in a particular sequence in a sentence. Since this research adopts the metalexical approach to antonymy, which postulates that the contrast relation among words is conceptual in nature, it starts from the premise that the factors of antonym ordering may follow from general cognitive principles. Since the distributional asymmetries in antonymic relation are attributed by some linguists to the concept of markedness (Vendler 1963; Givón 1970; Ljung 1974; Lehrer 1985; Handke 1995), this article will explore whether the standard markedness criteria are relevant in antonym ordering in actual language use.

\section{Theoretical background}

Some linguists prefer to keep the term antonym to refer to a specific sub-class of opposites expressed by scalar adjectives only (Lyons 1977; Lehrer and Lehrer 1982; Cruse 1986; Justeson and Katz 1991, Justeson and Katz 1992; Murphy and Andrew 1993; Mettinger 1994; Fellbaum 1995; Lehrer 2002; Karaman 2008). Scalar adjectives, which are gradable, as they represent degrees of a certain relevant property, provide the most typical examples of antonyms (e.g. hot/cold, long/ short). While Lyons (1977) and Cruse (1986) exclude all other types of binary semantic opposites from their antonymous category, Kempson (1977) suggests that only complementary opposites, which are not gradable, are truly antonymous, because complementary adjectives exhaustively bisect a domain (e.g. dead/alive, male/female). The other most common types of semantic oppositions cited in the literature include converse (e.g. parent/child, buy/sell, give/receive, above/below) and directional opposition (e.g. north/south, come/go, inside/outside). The disadvantages of such classifications are that they merely state that words with a certain kind of behaviour should be called antonymous, and the fact that they do not take into account the context of the opposition. On the other hand, Murphy (2003) presents a contextual approach to the classification of opposites, suggesting that all antonymous pairs share core antonym properties, and proposes using the terms antonyms and opposites interchangeably. She develops a theoretical model in which the antonym relation, as well as all other paradigmatic semantic relations, holds between words in use. As was stated earlier, the basic premise of the metalexical model of semantic relations is that they reflect conceptual knowledge about words, rather than lexical knowledge of words (Murphy 2000). After presenting a thorough and detailed account of the nine properties of semantic relations described in the literature ${ }^{2}$ Murphy (2003: 42-44) argues that they are all explicable by means of a single relational principle, which is able not only to explain but also to predict those relations in actual language use. An antonymic 
relation is defined on the basis of the principle Relation by Contrast - Lexical Contrast (RC-LC) which states that: "A lexical contrast set includes only wordconcepts that have all the same contextually relevant properties but one" (Murphy 2003: 170). The metalexical approach is pragmatic in nature, and takes into account the fact that in natural language use the number of antonyms of a particular word is greater than in neutral contexts. For example, in a neutral context, the pair sweet/sour seem to be better opposites in English than the pair sweet/bitter. However, depending on the context, sweet can have other opposites, including salty (in relation to popcorn), dry (in relation to white wine), bitter (in relation to liquid medicine) and so on. A context-dependent approach can explain these differences as it assumes that contextual cues may override semantic cues and preferences found without the context. This means that the context of the communicative use of the language determines the aspects of similarity and difference in a contrast set (Murphy 2003: 171). The definition of RC-LC predicts that the most prototypical examples of the relation involve items that differ in only one relevant point of meaning but, at the same time, that all instances of the relation of contrast are not different types of sematic opposition. Murphy also admits that there seems to be a small set of words that are closely linked both semantically and lexically, that are entrenched in memory and perceived as strongly coupled pairings by speakers. These pairs are referred to in the literature as canonical antonyms. The opposed pairs that are acknowledged as antonyms in thesauruses and dictionaries of antonyms are considered by some authors (Murphy 2003; Davies 2013) to be a part of the community canon.

\subsection{Corpus-based approaches to antonymy}

According to the syntagmatic approach, the meaning of a word is defined in terms of the company it keeps in language use, or in terms of the totality of its uses. In this respect, the syntagmatic approach opened up for corpus-based approaches to lexical semantics where contextual factors and real language use are the prime research objectives for the description of meanings. Following up on Charles and Millers' (1989) proposal that lexical associations between adjectival antonyms are formed through co-occurrence in sentences (the co-occurrence hypothesis) rather than substituting for one another in the same syntactic context (the substitution hypothesis), Justeson and Katz (1991, 1992) showed that very high co-occurrence rates appear for antonymous adjective pairs - a finding they claim supports the precondition for the formation of associations between words, shown experimentally by Deese $(1964,1965)$. They tested the co-occurrence hypothesis by examining the frequencies of the intersentential occurrences of adjectival antonyms in the Brown Corpus of English and confirmed that a set of adjectival antonyms co-occurred significantly more often than a set of random adjectives. Fellbaum (1995) conducted the first large scale corpus work that looked at a wider class of antonym pairs, including nouns and verbs. She looked at the co-occurrence of nominal and verbal antonyms in the Brown Corpus and found that antonyms in 
both groups co-occurred in the same sentence significantly more often than was the case by chance. Fellbaum also looked at the intersentential occurrences of morphologically related word pairs that express semantic opposition but do not belong to the same syntactic category, for example, pairs such as to begin and endless, or death and to live. Again, these cross-categorical antonym pairs co-occurred significantly more often than by chance, suggesting that antonyms do not have to belong to the same part of speech. These findings suggest that semantic opposition will be frequently expressed through antonymous concepts, and will not be restricted to word pairs from the same syntactic category.

Several studies in different languages investigated the relationship between syntactic frames and antonym co-occurrence in sentences. The largest and most systematic study of the textual functions of English antonyms was provided by Jones (2002) who described the contexts in which 56 traditionally recognized antonym pairs co-occurred within the sentence in a database of 3,000 sentences taken from The Independent newspaper corpus of 280 million words. The textual functions of the antonyms proposed by Jones are roughly related to specific English contrastive constructions. Jones distinguished eight textual functions of canonical antonyms, of which six were indicated by lexico-syntactic patterns. Antonyms are most frequently used in English journalistic texts to either indicate or emphasize another opposition between pairs of words or phrases in the same sentence (Ancillary Antonymy (38.7\%), e.g. I love to cook but I hate doing the dishes) or to signal the inclusiveness or exhaustiveness of a scale (Coordinated Antonymy (38.4\%), e.g. The government will encourage everyone, rich and poor). While Ancillary Antonymy was not defined by any patterns, Coordinated Antonymy was found in patterns like $X$ and $Y$, both $X$ and $Y, X$ or $Y$, whether/ either $X$ or $Y$, neither $X$ nor $Y, X$ as well as $Y$ and $X$ and $Y$ alike. Each of the other six (minor) textual functions of English antonyms accounts for about 5\% or less than 5\% of all the examples (Jones 2002: 41). These are: Distinguished Antonymy (antonyms within a framework that alludes to the semantic dissimilarity of those words, e.g. the difference between right and wrong), Transitional Antonymy (antonyms within a framework that expresses a movement or change from one location or state to another, e.g. hard currency has turned soft), Comparative Antonymy (antonyms within a framework that places them in a comparative context or measures them one against the other, e.g. more pessimistic than optimistic), Negated Antonymy (antonyms within a framework that negates one antonym to augment the other e.g. the good things, not the bad), Extreme Antonymy (patterns like to the very young and the very old) and Idiomatic Antonymy (a familiar idiom or proverb, e.g. easy come, easy go). Jones' functional framework provides a consistent description of the textual functions of antonymy, as they were found in other genres and registers of English (spoken English [Jones 2006 and Jones 2007], child and child-directed speech [Jones and Murphy 2005; Murphy and Jones 2008]) and in languages other than English (Swedish [Murphy et al. 2009], Japanese [Muehleisen and Isono 2009], Dutch [Lobanova et al. 2010], Serbian [Kostić 2011] and Chinese [Hsu 2015]). One important 
contribution of Lobanova's (2012) study is the finding that the functions of opposites in text are not limited by the surface pattern types in which canonical antonyms can be found, as her corpus-driven approach to studying antonymy was able to retrieve a wider range of opposites in a wider range of contexts. Using a small sets of six, twelve and eighteen seed pairs expressed by either adjectives, nouns or verbs, Lobanova (2012) identified the patterns for finding new pairs of opposites in a 450 million word newspaper corpus of Dutch. The algorithms devised were successful in finding patterns at the sentence level that are able to find good opposites expressed by adjectives, verbs and nouns, which makes them very useful for computational applications, such as that of the automatic identification of Contrast (Lobanova 2012: 227).

\subsection{Previous research on the sequence of English antonyms}

Among the studies that examine antonymy in actual language use in English, only Jones (2002) analyzed antonym ordering within the patterns of antonym co-occurrence in a sentence. Starting from the premise that antonyms are equal in many respects, Jones stated that we would not expect the members of an antonymous pair to have a marked and unmarked sequence in a text. In order to test this assumption, he investigated the sequence of all 56 pairs in all the textual functions of antonyms in his 3,000 sentences database, and concluded that the majority of pairs favored one sequence over the reverse of that sequence (Jones 2002: 120). More precisely, of the 56 pairs analyzed, in only 14 cases were the results obtained not statistically significant, which means that those pairs do not exhibit a tendency towards a specific ordering in the text. The sequence "rules" that Jones (2002) was able to identify are (in the order of influence): morphology (the root antonym precedes the derived one, e.g. correct/incorrect), positivity (the more positive antonym precedes the negative one, e.g. good/bad), magnitude (the antonym denoting more of a quantity precedes the one denoting less, e.g. large/ small), chronology (antonyms denoting temporal sequence in the real world reflect this sequence in the sentence, e.g. begin/end), gender (male precedes female and masculine precedes feminine in a statistically significant number of cases in the database), phonology (the shorter antonym tends to precede the longer one, e.g. boom/recession) and idiomaticity (one antonym precedes the other in a phrase which has a semi-idiomatic status, which in his database Jones applies only to 'war and peace' and 'dead or alive', the two pairs that disregard the factor of positivity). The remaining two factors, presented as only marginal criteria in the antonym sequence, are frequency and markedness. By markedness, Jones implies only semantic neutrality, in the sense that did you have a good time? is less biased than did you have a bad time?

Regarding frequency, Jones claims that it cannot be regarded as an influencing factor, because in a total of 56 word pairs examined (and this includes both the statistically significant and statistically insignificant results), the higher-frequency item comes first in 36 pairs, and also because he cites two counter-examples 
among the statistically significant antonym pairs (old is less frequent yet appears before new, as well as rich, being less frequent, appearing before poor). Still, one has to notice that almost all the other factors cited by Jones contain counterexamples as well ${ }^{3}$ but Jones did not consider them important enough to diminish the case for any of those factors. Positivity, as the second most important factor according to Jones, accounts for an even smaller number of pairs in his database ( $26^{4}$ of a total of 56$)$, but he did not seem to consider this important.

Markedness is not considered a cause of antonym sequence by Jones, mainly because of the overlaps between the criteria which determine markedness and the factors of antonym sequence that he identified (of which he mentioned positivity and morphology). However, this is an oversimplification, as the concept of markedness need not be defined in the narrow manner of Jones (by implying only semantic neutrality). Moreover, since positivity and morphology (the two most influential factors for antonym sequence in a text according to Jones) are widely cited in the literature as being among the criteria defining markedness, then his conclusion about the marginal status of markedness in antonym ordering is not warranted. As another reason for labelling markedness a less influential than all the other proposed factors, Jones (2002: 130) cited one counter-example from his corpus (young/old), offering it as evidence for his claim that not all antonymous pairs incline towards mentioning their unmarked term first. As was mentioned earlier, almost all the other factors can also be said to have counter-examples, and, as will be demonstrated in the discussion of the concept of markedness below, marks are not absolutes, but rather are constantly defined in terms of nonmarks and the context of which they are a part.

Finally, there are several pairs in Jones' database which he was not able to account for through any of the factors proposed. Some of those pairs did not appear in a statistically significant number of examples in either of the two possible orderings, and can be discounted (e.g. rural/urban, implicitly/explicitly, soft/hard, light/heavy, and so on). However, the proposed factors cannot account for hot/ cold either, nor for private/public and privately/publicly, for example. Although Jones notes that hot is the unmarked term with respect to cold, that public is twice as frequent as private, and publicly outnumbers privately by a ratio of 5:4, his conclusion was that their sequence "cannot be explained with reference to any of the usual criteria" (Jones 2002: 130). A brief examination of the sentences that feature antonyms in this reversed order in Jones' database leads to the general conclusion that the sequence "rules" are likely not to be obeyed when members of an antonymous pair are separated by more than one or two words in the text (Jones 2002: 132), which is the case when semantic and/or pragmatic conditions govern the antonym sequence (mostly in Ancillary Antonymy sentences in Jones database). When he examined the most influential factor of morphology in Coordinated Antonymy examples that flout the sequence rule, Jones admitted that in all the cases, contextual factors played a role in antonym sequencing, in the sense that the more significant, more common and expected member occurred first, and he regarded those cases as exceptions to the norm. However, another 
option would be to refer to the concept of markedness, since the above-mentioned properties that Jones noted are precisely the ones cited in the literature as the determinants of the status of the unmarked. If we know that markedness values are always context-sensitive, i.e. relevant given particular contexts, we could also postulate that all the "exceptions" to the norm are, in fact, not exceptions at all, on the condition that the factors of antonym ordering are explained in a different way. Before proceeding to the corpus analysis, the concept of markedness will be discussed in more detail.

\subsection{The concept of markedness}

The concept of markedness has been used in linguistics literature since the 1930s, when it was first defined by Nikolaj Trubetzkoy and Roman Jakobson, and basically refers to the hierarchical and therefore asymmetrical relationship between the poles of an opposition. Some linguists have even defined antonymy in terms of markedness (e.g. Vendler 1963; Givón 1970), claiming that in adjectival antonymous pairs, one of the members is unmarked in the sense of being a generic cover term for the common quality denoted by both members. The distinction between the unmarked and the marked antonymous adjective is further reflected in the dichotomy between the positive and the negative member, with the positive member denoting greater possession of the common quality involved in both members and the only one to be used in the unmarked or generic sense. It is typically used in certain syntactic constructions, e.g. how-questions with a weak stress on how (how big is the house? presupposes nothing about the size of the house, whereas how small is the house? presupposes that it falls below a certain generally accepted norm). Such a narrow definition of antonymy is not very useful, but it does point to the fact that markedness distinctions are prominent among gradable adjectives. Lehrer (1985) investigated a large number of gradable antonym pairs with respect to the properties of markedness, and concluded that $80 \%$ of common gradable antonym pairs have a markedness distinction. The most general criteria for markedness relevant to the study of adjectival antonyms are (Lehrer 1985: 398-400): the unmarked member is neutralized in questions and nominalizations (How tall/\#short is he?; warmth/\#coolth); the unmarked member appears in Quantity Measure Adjective phrases and with ratios (three feet tall/\#short; twice as old/\#young); the term with an overt mark is the marked member (happy/unhappy); the unmarked member is evaluatively positive (the marked is evaluatively negative) and denotes more of a quantity (good/bad; big/ little) and if there are asymmetrical entailments, the unmarked member is less likely to be biased or committed (e.g. $X$ is better than $Y: X$ may be good or bad; $X$ is worse than $Y: X$ must be bad). It should be noted that no single unmarked adjective must occur in all of these neutralized distributions. The member of the pair which displays the most unmarked characteristics is the unmarked member. In other words, not every unmarked item has the same set of these properties. It is interesting to note that Lehrer (1985) disregards the principle of frequency, 
proposed by Greenberg (1966) and Zwicky (1978), who state that the unmarked member has a greater frequency of use than the marked one. Lehrer's argument is that frequency follows from other criteria, such as neutralization or the use in quantity phrases and ratios. However, Haspelmath (2006) rejects this speculation and cites Leech et al. (2001), who showed that unmarked gradable adjectives are between twice and six times as frequent as their marked counterparts in the British National Corpus. Haspelmath points to the fact that such a striking difference cannot possibly be accounted for by neutralizing contexts like degree questions and measure phrases.

The unmarked/marked relationship can be conceptually represented as a figure/ground relationship, where the marked category is the figure and the unmarked one is the ground (Waugh 1982: 302). Although the unmarked form has so far been referred to as the one that has a more general meaning than the marked one, it can, in fact, have two interpretations. Outside any individuating context, it has the so-called "zero-interpretation" (Waugh 1982, following Jakobson), i.e. the most general, widest and broadest (and which corresponds to the ground). Within individuating contexts, it has the so-called "minus-interpretation", which signals "the absence of the unit of information associated with the marked term" (Waugh 1982: 303) and is therefore in implicit or explicit contrast to the marked form (this interpretation corresponds to the ground minus the figure conceptualization). So, for example, long is the unmarked item because it can be used as the opposite of short, and because it can be used as the carrier of the whole category (as in how long do you think this will last?); truth can stand for the whole dimension (as in with respect to truth value, this proposition is false) but can also denote one of the two choices within the dimension (truth versus falsity). More examples are provided by Waugh (1982), who discusses the semiotic status of life and death in our culture, showing that life is unmarked (in the sense of the 'zero-interpretation') with respect to death, as "we do not question at every moment of our lives whether the next moment should include life or death, or whether especially we should motivate our choice to live" (Waugh 1982: 313). The choice of death is in this respect marked, which points to the fact that death is the included element (the figure) and the hierarchically dependent one. On the other hand, in actual contexts of use, the difference between life and death can be a mutually exclusive one. The situation with life and death once again stresses the observation that the relations of markedness should always be understood as relevant with respect to the context, which makes markedness reversals possible. The most widely cited example in the literature is the reversal of male/female markedness status, with respect to whether the context implies professions typically held by men or women. Although commonly regarded as unmarked with respect to female in English (Leech 1974; Moulton 1981), male is definitely marked in the context of a nurse (a male nurse) or a secretary.

As the term "unmarked" has over time come to mean very much the same as "neutral", "normal", "frequent" or "expected", Haspelmath (2006) even suggests that the terms "marked" and "unmarked" can be dispensed with, proposing 
one of the above mentioned terms (among others) to replace it with. He in fact argues that a wide variety of asymmetries in language can be explained by frequency of use. Following Greenberg (1966), his position is that frequency/rarity in texts is the basic phenomenon that explains a lot of other linguistic phenomena. As the terms such as "distributionally unrestricted" versus "distributionally restricted" or "overtly coded" versus "uncoded" or "zero-coded" do not suggest a high degree of abstraction, nor have any explanatory depth, he argues that it is better to use frequency of use, which is "primary", in the sense that it explains the other markedness correlates. A category that is used more frequently will be both shorter and easier to process than a rarely used category (which is also well known from psychological literature), and conceptual difficulty is the cause of the lower frequency of a category. Therefore, the more frequent term of an opposition tends to be coded with less material or zero, and the more frequent term tends to be more widely distributed (Haspelmath 2006). Thus it could be concluded that the frequency with which forms are used influences their markedness relations. Since frequency of use correlates well with unmarked status, it can certainly be invoked as explanatory. Haspelmath (2006) notes that frequency asymmetries and expectations based on these also occur outside of language, citing Mayerthaler's (1988) example of clothing habits on beaches, where normally naked bathing is the marked case. However, on nudist beaches, we find a markedness reversal because wearing a bathing suit there would be unexpected, rare, and therefore marked.

Frequency of use has certain effects on cognitive representations which in turn lead to greater economy in the retrieval and production of linguistic units. Highfrequency items are stronger in their mental representations and therefore easier to access. In production, repetition leads to the automatization of neuromotor routines which over time shorten the duration of the sequence of gestures that make up a high-frequency word (Browman and Goldstein 1992; Mowrey and Pagliuca 1995). It means that the increase in efficiency in high-frequency words results from the way the general neuromotor system operates and is not restricted to language.

In the discussion on the concept of markedness a useful point can be made in establishing the human cognitive and physical make-up as the reference point for the unmarked. Clark and Clark (1978) discuss a number of markedness relationships in terms of human perception and cognition. They, for example, explain the phenomenon consistent across languages, of the unmarked item denoting more quantity while the marked one denotes less of the same quantity (e.g. long/short). They say, for length for example, that a line remains a line as it gets longer, but as it gets shorter, it will eventually disappear. Thus, the term meaning "having an extent" is more basic. Murphy (2003: 186) also points out the fact that scales are part of our conceptual knowledge about how measurement works. That knowledge prevents us from accepting short as the neutral term, as it describes a direction that goes toward the zero point (because tall designates the direction that goes away from the zero point), and measurement cannot start from the end 
of a scale that stretches on to infinity. Finally, Croft (2003: 88) explicitly claims that markedness is predicated of universal conceptual categories, and not particular linguistic categories, and that "the more general theoretical concepts are economic and iconic motivation, not typological markedness" (Croft 2003: 102).

\section{Materials and methods}

The antonym sample chosen for the purposes of this study contains antonymous pairs which differ in only one relevant point of meaning, according to the relational principle Relation by Contrast - Lexical Contrast ${ }^{5}$ (as proposed by Murphy 2003: 170). The majority of them are adjectival pairs, because "the best examples of minimal difference are those that are diametrically opposed and symmetrical since otherwise more than one minimal difference is involved" (Murphy 2003: 172). These adjectives describe properties that are relatively simple and are placed along the same dimension in a symmetrical way, occupying the opposite poles. The majority of the antonymous pairs discussed in the theoretical literature in English are also adjectival antonyms. Still, antonyms of other word classes were also included, as the relation of antonymy crosses part of speech boundaries. Fellbaum noted that "there is nothing special about antonymous adjectives $[\ldots]$ rather, there is something special about antonymous concepts, no matter in what form these concepts are lexicalized" (1995: 285). Therefore, the antonym sample includes five word classes and a total of fifty-six pre-chosen antonymous pairs. Among them there are 35 adjectival pairs, 8 nominal pairs, 6 verbal pairs, 4 adverbial pairs and 3 prepositional pairs. The list contains both lexical antonyms and morphologically related pairs. ${ }^{6}$ The list of antonyms accompanied by the number of sentences extracted for each pair (N.) is presented in Table 1.

Table 1. List of antonyms

\begin{tabular}{llllll} 
Antonyms & & N. & Antonyms & & N. \\
\hline big & small & 464 & happy & sad & 123 \\
male & female & 3,848 & right & wrong & 1,775 \\
old & new & 1,271 & wet & dry & 285 \\
young & old & 905 & shallow & deep & 35 \\
good & bad & 2,124 & correct & incorrect & 102 \\
black & white & 5,703 & left & right & 2,770 \\
easy & difficult & 59 & near & far & 242 \\
light & heavy & 68 & directly & indirectly & 884 \\
rich & poor & 954 & well & badly & 44 \\
dead & alive & 592 & officially & unofficially & 18 \\
internal & external & 1,232 & quickly & slowly & 29 \\
healthy & unhealthy & 41 & beginning & end & 320 \\
empty & full & 17 & war & peace & 705
\end{tabular}




\begin{tabular}{llllll} 
Antonyms & & $\mathrm{N}$. & Antonyms & & $\mathrm{N}$. \\
\hline open & closed & 213 & truth & lie & 6 \\
beautiful & ugly & 23 & love & hate & 163 \\
hot & cold & 594 & success & failure & 953 \\
early & late & 275 & top & bottom & 691 \\
high & low & 1,332 & life & death & 2,030 \\
light & dark & 611 & happiness & unhappiness & 12 \\
hard & soft & 199 & enter & exit & 88 \\
fast & slow & 134 & come & go & 1,300 \\
long & short & 451 & win & lose & 418 \\
happy & unhappy & 30 & rise & fall & 1,116 \\
cheap & expensive & 8 & create & destroy & 9 \\
strong & weak & 160 & give & take & 643 \\
true & false & 479 & before & after & 2,770 \\
successful & unsuccessful & 100 & in front of & behind & 73 \\
smart & stupid & 7 & above & below & 70
\end{tabular}

The next step was to choose the representative contexts of the antonym sequence in language use. As already mentioned, the investigation of the phrasal contexts of antonym co-occurrence in a sentence showed that the textual functions of English antonyms are tied to certain lexico-syntactic patterns. The textual function of inclusiveness (Coordinated Antonymy) is typified by antonyms co-occurring in grammatical contexts such as: $X$ or $Y$, (both) $X$ and $Y$, neither $X$ nor $Y$, whether/ either $X$ or $Y, X$ as well as $Y$ and $X$ and $Y$ alike. The second major textual function refers to the ability of an antonymous pair to create a binary contrast relation within the context of a sentence, but this function does not make use of any stable lexico-syntactic patterns. Some minor textual functions of antonyms make use of relatively stable phrasal contexts. However, not all the antonymous patterns in the sentence are representative for the study of antonym sequence. After a preliminary investigation of the corpus sentences featuring the pre-chosen antonyms in all their textual functions, it was decided that the only contexts appropriate for inclusion are contexts of inclusiveness. In those contexts, antonyms are minimally linked and both orderings mean the same thing, whereas in other textual functions the word order is very often determined by the syntactic function of the word in a sentence and/or information-structure demands. Such are the contexts of comparison (e.g. Anything that stands out naturally against its background has more of this "weight", and dark areas tend to be "heavier" than light ones), when antonyms act as lexical triggers of the wider contrast in a sentence (e.g. Fill up on potatoes, bread and pasta, which are high in carbohydrate and low in fat, but steer clear of rich, creamy sauces), when one member is negated solely with the aim of emphasizing the other (e.g. The inquiry was not the end of the argument, it was the beginning), when antonyms act as the parameters of a distinction (e.g. There are fears that the gulf between the country's rich and poor is growing) or when they mark the starting and ending points of a transition or change 
(e.g. Wool dyes very well, but avoid dramatic changes in water temperature, such as transferring from hot to cold water, otherwise it can shrink or stretch).

The methodology consisted of the following steps: a corpus search for the preselected antonymous pairs in the chosen patterns retrieved all the concordances which feature that word string from the corpus. The procedure was then repeated by reversing the order of the antonyms. The data was not sampled and included all the examples (a total of 40,202) containing the pre-chosen pairs (listed in Table 2) in the patterns of Coordinated Antonymy in The Corpus of Contemporary American English. ${ }^{7}$

The figures in Table 2 present the statistics of the antonym sequences for all fifty-six pairs. Column 1 features the antonym which comes first in more database examples, and Column 2 records the one that comes first in the fewer number of examples. In Column 3, the total number of contexts featuring both pairs in the database are recorded. The number of sentences that record the antonyms in the more frequent sequence is given in Column 4, which is followed by the same information expressed as a percentage (in Column 5). Column 6 provides information on the statistical significance of the results, based on a chi-square test (a $p$ value of below 0.05 was not considered statistically significant). Pairs are listed in descending strength of bias.

Table 2. Statistics of antonym sequence in the database

\begin{tabular}{llllll} 
A 1 & A2 & $\begin{array}{l}\text { Total } \\
\text { database } \\
\text { sentences }\end{array}$ & $\begin{array}{l}\text { More } \\
\text { frequent } \\
\text { sequence } \\
\text { (raw freq) }\end{array}$ & $\begin{array}{l}\text { More } \\
\text { frequent } \\
\text { sequence } \\
(\%)\end{array}$ & p value \\
\hline officially & unofficially & 18 & 18 & 100 & $<0.0001$ \\
smart & stupid & 7 & 7 & 100 & 0.0082 \\
truth & lie & 6 & 6 & 100 & 0.0143 \\
before & after & 2,770 & 2,754 & 99 & $<0.0001$ \\
directly & indirectly & 884 & 874 & 99 & $<0.0001$ \\
give & take & 643 & 635 & 99 & $<0.0001$ \\
win & lose & 418 & 413 & 99 & $<0.0001$ \\
right & wrong & 1,775 & 1,735 & 98 & $<0.0001$ \\
come & go & 1,300 & 1,273 & 98 & $<0.0001$ \\
true & false & 479 & 471 & 98 & $<0.0001$ \\
correct & incorrect & 102 & 100 & 98 & $<0.0001$ \\
rise & fall & 1,116 & 1,081 & 97 & $<0.0001$ \\
beginning & end & 320 & 311 & 97 & $<0.0001$ \\
healthy & unhealthy & 41 & 40 & 97 & $<0.0001$ \\
happy & unhappy & 30 & 29 & 97 & $<0.0001$ \\
good & bad & 2,124 & 2,040 & 96 & $<0.0001$ \\
early & late & 275 & 265 & 96 & $<0.0001$ \\
successful & unsuccessful & 100 & 96 & 96 & $<0.0001$ \\
life & death & 2,030 & 1,933 & 95 & $<0.0001$
\end{tabular}




\begin{tabular}{|c|c|c|c|c|c|}
\hline A 1 & $\mathrm{~A} 2$ & $\begin{array}{l}\text { Total } \\
\text { database } \\
\text { sentences }\end{array}$ & $\begin{array}{l}\text { More } \\
\text { frequent } \\
\text { sequence } \\
\text { (raw freq) }\end{array}$ & $\begin{array}{l}\text { More } \\
\text { frequent } \\
\text { sequence } \\
(\%)\end{array}$ & $\mathrm{p}$ value \\
\hline sucess & failure & 953 & 903 & 95 & $<0.0001$ \\
\hline top & bottom & 691 & 654 & 95 & $<0.0001$ \\
\hline big & small & 464 & 443 & 95 & $<0.0001$ \\
\hline rich & poor & 954 & 894 & 94 & $<0.0001$ \\
\hline enter & exit & 88 & 82 & 93 & $<0.0001$ \\
\hline above & below & 704 & 648 & 92 & $<0.0001$ \\
\hline happiness & unhappiness & 12 & 11 & 92 & 0.0039 \\
\hline male & female & 3,848 & 3,488 & 91 & $<0.0001$ \\
\hline well & badly & 44 & 40 & 91 & $<0.0001$ \\
\hline love & hate & 163 & 147 & 90 & $<0.0001$ \\
\hline hot & cold & 594 & 528 & 89 & $<0.0001$ \\
\hline happy & sad & 123 & 109 & 89 & $<0.0001$ \\
\hline create & destroy & 9 & 8 & 89 & 0.0196 \\
\hline black & white & 5,703 & 4,956 & 87 & $<0.0001$ \\
\hline war & peace & 705 & 614 & 87 & $<0.0001$ \\
\hline cheap & expensive & 8 & 7 & 87 & 0.0339 \\
\hline high & low & 1,332 & 1,115 & 84 & $<0.0001$ \\
\hline near & far & 242 & 204 & 84 & $<0.0001$ \\
\hline open & closed & 213 & 174 & 82 & $<0.0001$ \\
\hline in front of & behind & 73 & 60 & 82 & $<0.0001$ \\
\hline young & old & 905 & 719 & 80 & $<0.0001$ \\
\hline wet & dry & 285 & 225 & 79 & $<0.0001$ \\
\hline fast & slow & 134 & 106 & 79 & $<0.0001$ \\
\hline quickly & slowly & 29 & 23 & 79 & 0.0016 \\
\hline old & new & 1,271 & 986 & 77 & $<0.0001$ \\
\hline light & dark & 611 & 474 & 77 & $<0.0001$ \\
\hline internal & external & 1,232 & 924 & 75 & $<0.0001$ \\
\hline strong & weak & 160 & 114 & 71 & $<0.0001$ \\
\hline full & empty & 17 & 12 & 71 & 0.0896 \\
\hline beautiful & ugly & 23 & 16 & 69 & 0.0606 \\
\hline left & right & 2,770 & 1,845 & 67 & $<0.0001$ \\
\hline hard & soft & 199 & 133 & 67 & $<0.0001$ \\
\hline easy & difficult & 59 & 39 & 66 & 0.0134 \\
\hline shallow & deep & 35 & 23 & 66 & 0.0630 \\
\hline dead & alive & 592 & 377 & 64 & $<0.0001$ \\
\hline long & short & 451 & 254 & 56 & 0.0073 \\
\hline light & heavy & 68 & 38 & 56 & 0.3320 \\
\hline
\end{tabular}

Among the fifty-six English antonyms chosen for this analysis, 52 pairs exhibit a statistically significant preference towards one of the two possible orderings, 
which make up $93 \%$ of all pairs. The remaining 4 pairs, whose chi-square test results generated a $\mathrm{p}$ value above 0.05 , cannot be said to have any preference towards either of the two orderings. These include the adjectival pairs full/empty, beautiful/ugly, shallow/deep, and light/heavy. The first member of these pairs appeared before the second member in a larger number of sentential contexts, but the frequency of use in that order versus the frequency of the reversed order is not valid enough to be considered important. In other words, there is not enough evidence to claim that any of these 4 antonymous pairs exhibits any dominant sequence in language use.

The distributional asymmetry of the other 52 antonymous pairs is statistically significant. More than one half of those (28, more precisely) are recorded in the dominant order in over $90 \%$ of all occurrences in the database, which demonstrates a very strong commitment to the preferred order. These are the adjectival pairs smart/stupid, right/wrong, true/false, correct/incorrect, healthy/unhealthy, happy/unhappy, good/bad, early/late, successful/unsuccessful, big/small, rich/ poor, male/female; the nominal pairs truth/lie, beginning/end, life/death, success/ failure, top/bottom, happiness/unhappiness; the verbal pairs give/take, win/lose, come/go, rise/fall, enter/exit; the adverbial pairs officially/unofficially, directly/ indirectly, well/badly; and the prepositional pairs before/after, above/below. Among another 12 pairs, the proportion of the more frequent sequence ranges between $80 \%$ and $90 \%$ of all the contexts extracted. These include the antonymous adjectives hot/cold, happy/sad, black/white, cheap/expensive, high/low, near/far, open/closed, young/old, the nouns love/hate, war/peace, verbs create/ destroy, and the prepositional pair in front of/behind. The last group of antonyms comprises another 12 pairs, which exhibit a preference of $56 \%$ of all examples in the case of long/short, between $64 \%$ and $67 \%$ in the cases of dead/alive, easy/difficult, hard/soft, left/right, and between $71 \%$ and $79 \%$ for strong/weak, internal/ external, light/dark, old/new, quickly/slowly, fast/slow and wet/dry.

\section{Factors in antonym ordering}

The data presented in Table 2 show that an overwhelming majority of $93 \%$ of all the antonymous pairs pre-selected for this study exhibit a preferred order in language use. This section identifies and examines the reasons why language users give preference to one sequence over the reverse of that sequence. Bearing in mind the determinants of the property of markedness discussed in the literature (especially where adjectival antonyms are concerned), as well as the results of Jones' (2002) analysis of the sequence of English antonyms in journalistic texts, it will be of special interest to explore whether the criteria for determining markedness can be identified as factors of antonym ordering, and whether the concept of markedness is a relevant principle of antonym sequence in language use. The determinants that govern the ordering of antonyms in the database are summarized in Table 3, for each antonymous pair individually. As was the case in Table 2, Column 1 presents 
the antonym which comes first in more database examples (A1), and Column 2 records the one that comes first in fewer examples (A2). Column 3 records the word frequencies of $\mathrm{A} 1$ and $\mathrm{A} 2$ in the entire corpus of 450 million words. The remaining columns record the established criteria, ordered according to the number of pairs affected by the given criterion (with the exception of morphology, for reasons that will be explained below). A question mark indicates a tentative claim regarding the validity of the criterion for the given antonymous pair.

Table 3. Factors in antonym ordering

\begin{tabular}{|c|c|c|c|c|c|c|c|c|}
\hline A 1 & A 2 & 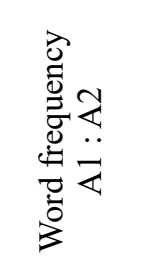 & 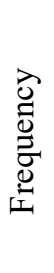 & $\begin{array}{l}\text { के } \\
0 \\
\frac{0}{0} \\
\frac{1}{0} \\
\frac{0}{0} \\
\sum\end{array}$ & 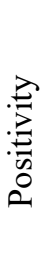 & 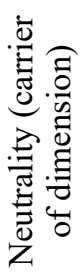 & 㤂 & 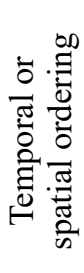 \\
\hline healthy & unhealthy & $\begin{array}{c}27,340: \\
1,866\end{array}$ & $\mathrm{x}$ & $\mathrm{x}$ & $\mathrm{x}$ & $\mathrm{x}$ & $?$ & \\
\hline happy & unhappy & $\begin{array}{c}55,400: \\
5,763\end{array}$ & $\mathrm{x}$ & $\mathrm{x}$ & $\mathrm{x}$ & & & \\
\hline successful & unsuccessful & $\begin{array}{c}40,400: \\
2,711\end{array}$ & $x$ & $x$ & $x$ & & & \\
\hline correct & incorrect & $\begin{array}{c}28,930: \\
3,139\end{array}$ & $\mathrm{x}$ & $\mathrm{x}$ & $\mathrm{x}$ & & & \\
\hline happiness & unhappiness & $\begin{array}{c}\text { 8,040: } \\
993\end{array}$ & $\mathrm{x}$ & $\mathrm{x}$ & $\mathrm{x}$ & & & \\
\hline directly & indirectly & $\begin{array}{c}38,467: \\
3,134\end{array}$ & $x$ & $\mathrm{x}$ & & & & \\
\hline officially & unofficially & $\begin{array}{c}7,492: \\
343\end{array}$ & $x$ & $\mathrm{x}$ & & & & \\
\hline male & female & $\begin{array}{c}43,910: \\
43,002\end{array}$ & $\mathrm{x}$ & & & & & \\
\hline good & bad & $\begin{array}{c}415,950: \\
98,986\end{array}$ & $x$ & & $\mathrm{x}$ & $\mathrm{x}$ & $?$ & \\
\hline true & false & $\begin{array}{c}90,165: \\
14,944\end{array}$ & $\mathrm{x}$ & & $\mathrm{x}$ & $\mathrm{x}$ & & \\
\hline life & death & $\begin{array}{c}318,368: \\
94,573\end{array}$ & $x$ & & $x$ & $\mathrm{x}$ & & \\
\hline truth & lie & $\begin{array}{c}48,466: \\
24,680\end{array}$ & $\mathrm{x}$ & & $\mathrm{x}$ & $\mathrm{x}$ & & \\
\hline well & badly & $\begin{array}{c}570,870: \\
10,992\end{array}$ & $\mathrm{x}$ & & $\mathrm{x}$ & $\mathrm{x}$ & $?$ & \\
\hline strong & weak & $\begin{array}{c}75,492: \\
16,089\end{array}$ & $\mathrm{x}$ & & $\mathrm{x}$ & $\mathrm{x}$ & $\mathrm{x}$ & \\
\hline
\end{tabular}


THE DISTRIBUTIONAL ASYMMETRIES OF ENGLISH ANTONYMS IN LANGUAGE USE 21

\begin{tabular}{|c|c|c|c|c|c|c|c|c|}
\hline A 1 & A 2 & 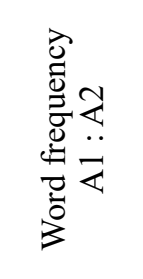 & 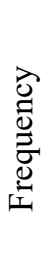 & 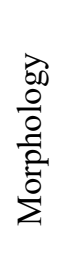 & 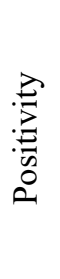 & 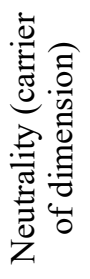 & $\begin{array}{l}\stackrel{己}{\stackrel{\Xi}{\Xi}} \\
\stackrel{\Xi}{\Xi} \\
\stackrel{\Xi}{\Xi}\end{array}$ & 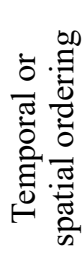 \\
\hline smart & stupid & $\begin{array}{c}21,594: \\
14,286\end{array}$ & $\mathrm{x}$ & & $\mathrm{x}$ & $\mathrm{x}$ & $?$ & \\
\hline happy & sad & $\begin{array}{c}55,400: \\
17,549\end{array}$ & $\mathrm{x}$ & & $\mathrm{x}$ & & & \\
\hline right & wrong & $\begin{array}{c}486,188: \\
76,229\end{array}$ & $\mathrm{x}$ & & $\mathrm{x}$ & & & \\
\hline love & hate & $\begin{array}{c}152,358: \\
20,615\end{array}$ & $\mathrm{x}$ & & $\mathrm{x}$ & & & \\
\hline success & failure & $\begin{array}{l}54,000: \\
27,230\end{array}$ & $\mathrm{x}$ & & $\mathrm{x}$ & & & \\
\hline win & lose & $\begin{array}{l}56,221: \\
39,415\end{array}$ & $\mathrm{X}$ & & $\mathrm{x}$ & & & \\
\hline create & destroy & $\begin{array}{c}55,350: \\
10,757\end{array}$ & $\mathrm{x}$ & & $\mathrm{x}$ & & & \\
\hline light & dark & $\begin{array}{c}113,179: \\
67,620\end{array}$ & $\mathrm{x}$ & & $?$ & & & \\
\hline big & small & $\begin{array}{c}207,250: \\
180,231\end{array}$ & $\mathrm{X}$ & & & $\mathrm{x}$ & $\mathrm{x}$ & \\
\hline hot & cold & $\begin{array}{c}58,230: \\
58,174\end{array}$ & $\mathrm{x}$ & & & $\mathrm{x}$ & $\mathrm{X}$ & \\
\hline high & low & $\begin{array}{c}209,144: \\
74,012\end{array}$ & $\mathrm{x}$ & & & $\mathrm{x}$ & $\mathrm{X}$ & \\
\hline fast & slow & $\begin{array}{c}42,163: \\
31,708\end{array}$ & $\mathrm{x}$ & & & $\mathrm{x}$ & $\mathrm{x}$ & \\
\hline quickly & slowly & $\begin{array}{l}64,715: \\
37,189\end{array}$ & $\mathrm{x}$ & & & $\mathrm{x}$ & $\mathrm{X}$ & \\
\hline long & short & $\begin{array}{c}275,960: \\
72,716\end{array}$ & $\mathrm{x}$ & & & $\mathrm{x}$ & $\mathrm{X}$ & \\
\hline top & bottom & $\begin{array}{c}128,166: \\
41,510\end{array}$ & $\mathrm{x}$ & & & & $?$ & \\
\hline above & below & $\begin{array}{l}81,091: \\
48,673\end{array}$ & $\mathrm{x}$ & & & & $?$ & \\
\hline dead & alive & $\begin{array}{l}\text { 68,831: } \\
27,845\end{array}$ & $\mathrm{x}$ & & & & & \\
\hline internal & external & $\begin{array}{c}24,810: \\
13,520\end{array}$ & $\mathrm{x}$ & & & & & \\
\hline open & closed & $\begin{array}{c}130,185: \\
39,856\end{array}$ & $\mathrm{x}$ & & & & & \\
\hline war & peace & $\begin{array}{c}178,115: \\
47,264\end{array}$ & $\mathrm{x}$ & & & & & \\
\hline
\end{tabular}




\begin{tabular}{|c|c|c|c|c|c|c|c|c|}
\hline A 1 & A 2 & 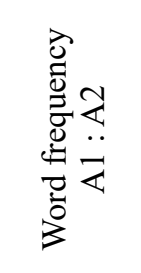 & 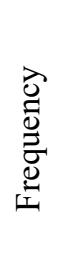 & 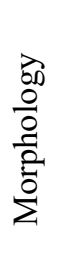 & 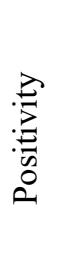 & 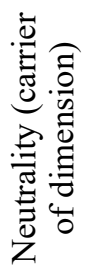 & 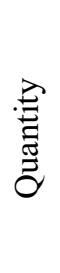 & 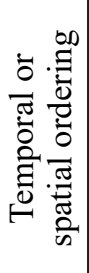 \\
\hline left & right & $\begin{array}{c}22,758: \\
19,172\end{array}$ & $\mathrm{x}$ & & & & & \\
\hline hard & soft & $\begin{array}{c}135,912: \\
28,998\end{array}$ & $\mathrm{x}$ & & & & & \\
\hline early & late & $\begin{array}{c}141,525: \\
90,534\end{array}$ & $\mathrm{x}$ & & & & & $\mathrm{x}$ \\
\hline enter & exit & $\begin{array}{c}\text { 21,573: } \\
9,489\end{array}$ & $\mathrm{x}$ & & & & & \\
\hline rich & poor & $\begin{array}{c}39,324: \\
55,649\end{array}$ & & & $\mathrm{x}$ & & & \\
\hline give & take & $\begin{array}{l}167,161: \\
333,477\end{array}$ & & & $\mathrm{x}$ & & & \\
\hline cheap & expensive & $\begin{array}{l}\text { 13,543: } \\
24,982\end{array}$ & & & $\mathrm{x}$ & & & \\
\hline easy & difficult & $\begin{array}{l}65,942: \\
72,543 \\
\end{array}$ & & & $\mathrm{x}$ & & & \\
\hline black & white & $\begin{array}{l}176,735: \\
208,113\end{array}$ & & & & & $\mathrm{x}$ & \\
\hline wet & dry & $\begin{array}{l}17,840: \\
31,630\end{array}$ & & & & & $\mathrm{x}$ & \\
\hline rise & fall & $\begin{array}{c}33,099: \\
67,561 \\
\end{array}$ & & & & & $\mathrm{x}$ & \\
\hline old & new & $\begin{array}{r}206,008: \\
710,615\end{array}$ & & & & $\mathrm{x}$ & $\mathrm{x}$ & \\
\hline beginning & end & $\begin{array}{l}59,285: \\
189,211\end{array}$ & & & & & & $\mathrm{x}$ \\
\hline come & go & $\begin{array}{r}310,137: \\
429,982 \\
\end{array}$ & & & & & & $\mathrm{x}$ \\
\hline before & after & $\begin{array}{r}385,451: \\
523,738 \\
\end{array}$ & & & & & & $\mathrm{x}$ \\
\hline in front of & behind & $\begin{array}{l}42,925: \\
129,218\end{array}$ & & & & & & $\mathrm{x}$ \\
\hline near & far & $\begin{array}{l}77,141: \\
155,812 \\
\end{array}$ & & & & & & $\mathrm{x}$ \\
\hline young & old & $\begin{array}{l}160,246: \\
206,008\end{array}$ & & & & & & $\mathrm{x}$ \\
\hline
\end{tabular}

Table 3 lists all the antonymous pairs (a total of 52) whose sequence statistics were established as significant enough to be included in the analysis of the factors that govern antonym ordering in language use. All the pairs are influenced by one 
or more of the six factors presented, but the factors themselves are not of equal importance and status.

\subsection{Frequency}

The criterion of frequency is the most pervasive one, accounting for a total of 38 pairs, which amounts to three quarters of all the pairs analyzed. This criterion implies that the more frequent word of the two members of an antonymous pair comes first when the antonyms are ordered in language use. Following Greenberg's (1966) and Haspelmath's (2006) claims about the importance of frequency asymmetries to language phenomena, a corpus search for all the occurrences of each member of all the pre-selected antonymous pairs was performed, and those data are recorded in Column 3. Corpus data indicate that frequency asymmetries do exist for the largest number of antonymous pairs, ${ }^{8}$ which shows that word frequency can be regarded as the most important criterion of antonym ordering. The pairs that exhibit the largest frequency asymmetries are, for example, well/ badly (the first mentioned word is 52 times more frequent), officially/unofficially (officially is 21.8 times more frequent than unofficially), successful/unsuccessful (the first word outnumbers the second 14.9 times), healthy/unhealthy (the first antonym is 14.6 times more frequent than the second), directly/indirectly (12.3 times), happy/unhappy (9.6 times), correct/incorrect (correct is 9.2 times more frequent than incorrect), happiness/unhappiness (8 times), love/hate (7.4 times) and right/wrong (6.4 times). In terms of all the other pairs, the A1 member is between two and six times more frequent than the A2 member. The explanatory power of the criterion of frequency is unquestionable, and corpus data provide ample evidence for the claim that the strength of this factor cannot be disregarded in any analysis of antonym sequences in a text.

The criterion of frequency is superior to the criterion of morphology (in Column 5), as all seven morphological antonyms put the root word first. The disproportions in this group of antonyms vary from happiness being 8 times more frequent than unhappiness, to officially being 21.8 times more frequent than unofficially. Morphology has been presented in Table 3 as a separate factor because it is one of the determinants of markedness and because a previous study of antonym sequence in English (Jones 2002) treated it as the most influential factor in antonym ordering. Based on corpus evidence and word frequency statistics, we argue that morphology need not be treated as a separate factor of antonym ordering, since it always follows on from the criterion of frequency, i.e. shorter words are more frequent than longer words. Furthermore, in comparison to morphology, frequency is an explanatory principle of greater power.

In Table 3, the dominant sequence of male/female order in the database is attributed to the criterion of frequency, since male is slightly more frequent than female in the entire corpus (it occurs 43,910 times compared to 43,002 occurrences of female). The preference of male versus female can at the same time be attributed to the unmarked/marked distinction, as masculine gender is unmarked in the 
grammatical systems of some languages (e.g. French, English). This markedness distinction is demonstrated in some languages by the fact that job titles in the feminine gender are always formed by derivational suffixes added to the corresponding masculine gender terms (e.g. in Croatian or Serbian, among others). If the male/female markedness distinction is pervasive cross-culturally, no matter whether male or female is the unmarked term, then its importance cannot be diminished. It is also possible that the unmarked status of the masculine gender is reflected in language use in a tendency for things male to be given priority over things female, which would mean that in this case gender could be regarded as another factor of antonym ordering in language use.

\subsection{Positivity}

The sixth column in Table 3 records data on the criterion of positivity, and this criterion implies that if one member of an antonymous pair has more positive connotations than the other one, it is mentioned first. Lyons (1977:276) also noted that "the positive opposite tends to precede the negative when opposites are co-ordinated". Jones (2002) also stressed the importance of this factor, citing it as the second most influential factor in the antonym sequence in his database. This criterion was also noted in various articles on markedness distinctions in adjectival antonyms (Vendler 1963; Givón 1970; Lehrer 1985, among others) and is claimed to pertain to the unmarked member of the opposition. This is the reason why positivity has been assigned a separate column in Table 3 . The factor of positivity can be applied to almost one half of all the pairs on the list (to 23 pairs, more precisely), and is relevant in the ordering of the adjectives healthy/unhealthy, happy/unhappy, successful/unsuccessful, correct/incorrect, good/bad, true/false, strong/weak, smart/ stupid, happy/sad, right/wrong, rich/poor, cheap/expensive, ${ }^{9}$ easy/difficult and possibly light/dark; the nouns happiness/unhappiness, life/death, truth/lie, love/ hate and success/failure; the verbs win/lose, create/destroy and give/take ${ }^{10}$ and the adverbs well/badly. All these pairs follow a simple pattern: antonyms with positive associations are given priority over antonyms with negative associations. What can also be noted with respect to these pairs is that about one fifth of them are at the same time influenced by morphology, and this factor has already been explained in terms of frequency. Moreover, a closer look at the twenty-three pairs with the positive antonym - negative antonym pattern reveals that in more than four fifths of the cases (19 out of 23) the more frequent antonym covers the A1 position. In other words, the order of the huge majority of the antonymous pairs influenced by positivity is at the same time governed by the criterion of frequency, since the more positive member is at the same time the more frequent one in the whole corpus of 450 million words. The implications of the observation that the more positive antonym also tends to be the more frequent one will be dealt with in Section 5. At this point, it can be said that the superiority of the criterion of frequency is demonstrated by its ability to subsume the criterion of morphology, and to be a major contributing factor to the criterion of positivity (where positivity is applicable). 


\subsection{Neutrality and quantity}

The seventh column in Table 3 refers to the notion of neutrality or the carrier of dimension, which is an important concept in the treatment of markedness, as it refers to the unmarked member (cf. Waugh 1982). It corresponds to the zero interpretation of the unmarked member, i.e. the one in which it can stand for the whole category, and which is conceptually represented as the ground in any figure/ground organization. A gradable adjective (one that can be used in comparisons), which can be identified as the carrier of dimension, is neutral in how-questions, in the sense of not carrying any presuppositions. For example, questions such as how healthy/good/strong/smart/big/hot/high/fast/long/old is he/she/it? or how well do you remember / how quickly did it happen? are not biased in the sense in which the other member of each of those antonyms would be in the same context. However, neutrality need not be restricted only to contexts characteristic of gradable adjectives. Waugh (1982) argues that nouns such as truth and life can also stand for the whole dimension, and gives evidence of the contexts in which this appears (e.g. the context of the truth value of a proposition, or the observation that life in general needs no motivation while death does). Likewise, it is not difficult to think of a context in which the corresponding adjective true can also be used neutrally (e.g. how true is his statement?). To sum up, the more frequent order of the fifteen pairs from the list can be attributed to the fact that the A1 member is the carrier of dimension and therefore can be used neutrally.

For the ten gradable adjectives and two adverbs among the fifteen pairs influenced by the criterion of neutrality, the criterion of quantity (presented in Column 8) applies as well, as the A1 members are all conceptualized as denoting more of a quantity along the same meaning dimension. It means that the criterion of quantity (or "magnitude" in Jones' terminology) follows from the principle of neutrality in cases in which it is applicable. This might raise the question of whether it needs to be considered as a separate factor of antonym ordering at all. However, there are three antonymous pairs whose preferred ordering in language use can only be attributed to the criterion of quantity, at least in our database. These are black/white, wet/dry and rise/fall. At first sight, it might be surprising that the pair black/white is not under the influence of the criterion of neutrality, knowing that white light is the presence of all color, which can be demonstrated by shining it through a spectrum which splits white light into its component parts. White is also the more frequent word in the corpus, 1.2 times more frequent than black, and the one carrying the more positive connotations. However, color is a perception that depends on the responses of the human visual system to light and the interaction of light with objects. We usually see color in the form of pigments, not light. Thus, white is the presence of all color when you are mixing light, but it works exactly opposite when mixing pigment. On the other hand, black is the densest color, and creates perceptions of heaviness or, in other words, more of the (pigment) quantity. The preferred ordering of wet/dry can be attributed to the fact that wet implies having more of the property, which is more basic in the human 
conceptualization of how measurement works. Quantity can also be considered relevant in the preferred order of the verbal pair rise/fall, whose subjects in the database sentences exhibit more of the quality of height in the first word in this pair. It could even be argued that the criterion of quantity is also applicable in pairs like top/bottom and above/below, on the grounds that the object has more of the quality of height in the first word in each pair.

An important observation can be made regarding the relationship between the criteria of frequency and neutrality. The data in Table 3 demonstrate that 14 out of 15 antonymous pairs, whose sequence is governed by the criterion of neutrality, are also influenced by frequency, since the A1 member of each of those 14 pairs is at the same time the more frequent one. Such a strong correlation between the criteria of frequency (as the most pervasive of all the criteria of antonym sequence and the one of the determinants of markedness) and neutrality (as one of the most general properties of the status of the unmarked) seems to point to the conclusion that the concept of markedness is an all-important one in antonym ordering in language use.

\subsection{Temporal and visual-spatial ordering}

If one antonym is prone to temporally preceding the other in the real world, this sequence will be reflected in the order of the antonyms in the sentence. This kind of correlation was also noted by Croft (2003), who claims that asymmetries among linguistic elements may be explainable in terms of iconism between the structure of language and the conceptualization of the world. The last column in Table 3 records the pairs whose sequence is governed by either temporal or visual-spatial ordering (or both). The temporal ordering of events in the real world is reflected in the more dominant sequence of early/late (e.g. early morning precedes late morning), young/old (in the sense that one is ten years old before one is fifty years old), beginning/end, come/go (in the database sentences which contain this antonymous pair the action of coming to a place temporally precedes the action of leaving it) and before/after. Both temporal and visual-spatial orderings apply to the preferred sequence of near/far, which are in the 242 database sentences, used either metaphorically in the temporal sense of soon/late, or in the visual-spatial sense of close/distant in relation to the observer. In all these contexts, what happens earlier in time precedes what comes next, and what is observed first (because it is more easily visually accessible) precedes that which is observed less easily, as it requires greater processing effort (from the perspective of the observer's own body). The perceptual ordering within visual-spatial perception, in the sense of viewing relationships from the perspective of the observer's own body, governs the dominant sequence of the pair in front of/behind. Sixty of the 73 database sentences testify that what comes "in front of" precedes that which comes "behind", because it is the first to be observed and more easily accessible, from the perspective of the writer's/observer's own body, in the context of the perception of external visual space. 


\section{Discussion and conclusion}

The results of this study testify that there is a strong correlation between the ordering of English antonyms in language use and the concept of markedness, as it is defined and described in the literature, mostly on adjectival antonyms. The order of antonyms in contexts in which they are coordinated and in which both orderings have the same meaning is generally, but not exclusively, dictated by the most widely cited markedness criteria, such as word frequency (the more frequent antonym comes first), morphology (the root antonym precedes the derived one), positivity (the more positive antonym comes first), neutrality (the generic cover term is put before the more specific one) and quantity (the antonym denoting greater possession of the common quality involved in both members precedes the one denoting less). The proposed factors are not of equal status and importance, in the sense that some are more basic while others derive from them and are applicable depending on the semantic and morphological structure of the given antonyms. It is argued that the more basic criteria are word frequency, positivity and quantity, while morphology and neutrality are regarded as criteria which follow on from the frequency of use or quantity. Frequency of use is not applicable in only 14 of the 52 pairs whose preferred order is statistically significant. These include the six pairs influenced by temporal and/or visual-spatial ordering, four pairs influenced by quantity (black/white, wet/dry, rise/fall and old/ new) and four pairs influenced by positivity (rich/poor, giveltake, cheap/expensive and easy/difficult). It could also be argued that the choice of antonym sample and the size of the corpus may have influenced the results. This research on the order of English antonyms shows that not all antonyms that have positive connotations are necessarily the more frequent members of the pair. However, there is some evidence in the literature that words with positive meaning tend to be more frequently and more diversely used cross-culturally. This point will be returned to later in the discussion.

The markedness criteria discussed in the theoretical literature on English antonyms cannot account for the sequence of all the antonymous pairs. The criteria of temporal and visual-spatial ordering are argued to govern the sequence of antonymous pairs which are iconic of extralinguistic temporal sequences and the ordering within visual-spatial perception from the perspective of the observer's own body. Along with the principle of markedness, these criteria should be regarded as the basic principles of antonym ordering in language use because they relate to the human ability to conceptualize time and directional concepts. In other words, it is claimed that antonym sequence in language use is influenced by the principle of markedness (through its determinants such as word frequency, positivity, quantity and neutrality) and the principles of temporal and visual-spatial ordering. Therefore, a clear general pattern can be identified in cases in which both antonym orderings mean the same thing: the more frequent, positive, more basic or expected member of the pair is used before the less frequent, less positive or less expected and therefore marked member. It should be noted that not every 
unmarked member has the same set of these properties. Moreover, since marks are not absolute but always defined in terms of the contexts in which they are used, it is possible that even when the more dominant antonym sequence is reversed, antonym ordering in language use may still follow a very general, unmarked - marked, pattern. The dominant antonym sequence may be overruled by more pressing discourse needs, but without violating the principle of markedness in the sense that the unmarked member is used before the marked one, in that specific context.

This research differs from the previous study of antonym sequence in English (Jones 2002) with respect to the methodology, the size of the database and the treatment of the concept of markedness, which resulted in a much higher proportion of statistically relevant pairs and led to different conclusions regarding the principles of antonym ordering in language use. The antonymous pairs analyzed in these two studies are not identical, although certain pairs do appear on both lists. Jones' research was based on 3,000 examples of the fifty-six pairs in all the textual functions of antonyms randomly extracted from the 280 million word corpus of British journalistic texts. In this study, all the textual functions except the function of inclusiveness were disregarded on the grounds of not being representative of sequence patterns, and the data extracted from the 450 million word balanced corpus of American English were not sampled. The more important differences pertain to the factors of antonym ordering, as Jones proposed seven sequence rules (morphology, positivity, magnitude, chronology, gender, phonology and idiomaticity), claiming that frequency and markedness can at best be regarded an only marginal criteria in any antonym sequence. Moreover, he was not able to define the preferred sequence pattern for several pairs in his database (according to the rules he proposed), to adequately classify the counter examples, or to accomodate for sentences featuring antonyms in the reversed order (see Section 2.2). As a result, he concluded that the rules of antonym sequence are not rigid grammar rules and can be either broken or obeyed.

The findings of this study point to the conclusion that the distributional asymmetries of antonyms in language use may follow a pattern in which the unmarked member (in the sense of more common, basic and expected with respect to conceptual representations) precedes the marked member. A deeper issue is to pinpoint the reasons for markedness distinctions in the context of antonym ordering in language use. Starting from the metalexical approach to antonymy, which treats it as a conceptual relation, the initial premise was that the ordering factors of antonym sequences may derive from general cognitive principles and conceptual representations. There is evidence in the literature that word frequency, positivity, neutrality, quantity, temporal and visual-spatial ordering are important in human conceptual representations. It has been experimentally shown that higher-frequency items are stronger in mental representation and easier to access, and that the increase in efficiency in higher-frequency words results from the way the general neuromotor system operates (Browman and Goldstein 1992; Mowrey and Pagliuca 1995). There is a universal human tendency (Boucher and 
Osgood 1969) to use evaluatively positive words more frequently and diversely than evaluatively negative words in communicating, and negative affixes are applied significantly more often to the positive members of pairs (to make the negative opposite) than to the negative members (to make the positive opposite). The unmarked/marked relationship is the metaphorical representation of the figure/ ground conceptualization, a type of perceptual grouping which is a vital necessity for recognizing objects through vision. Gestalt psychologists held that shaped entities simply do not exist prior to this figure-ground assignment. The conceptualization of scales governs our conceptual knowledge about how measurement works, which implies that "having an extent" is more basic (Murphy 2003). Visual-spatial ordering and temporal ordering are two ordering systems in which data or information may be arranged. Spatial ordering arranges data in a gestalt or configuration, and one of the elements of the concept of spatial perception is the capacity to view spatial relationships (right and left, front and back, up and down) from the perspective of the observer's own body (Thurstone 1950). The ability to locate objects in space and the ability to orient ourselves with respect to external objects are dependent upon the representation of visual space within the nervous system. Temporal ordering arranges data in a sequence or linear chunk and is an important part of our cognitive abilities.

The distributional asymmetries of antonymous pairs in language use exist because antonymy is a conceptual relation. However, the concepts or referents that antonyms represent may not always be in a symmetrical relationship. Antonym orderings follow a pattern in which the unmarked member (that which is more common, basic and expected) precedes the marked member. This general distributional principle derives from general cognitive principles and conceptual information.

\section{Notes}

1 The Corpus of Contemporary American English (COCA) is the largest freely-available corpus of English, and the only large and balanced corpus of American English. The corpus was created by Mark Davies of Brigham Young University, contains more than 450 million words of text and is available at http://corpus.byu.edu/coca/.

2 These properties are: productivity, binarity, variability, prototypicality, canonicity, semisemanticity, unaccountability, predictability and universality (see Murphy 2003: 26-42).

The only exceptions being gender, idiomaticity and morphology, which have a very limited descriptive power as factors of antonym sequence. Gender accounts for essentially one pair, idiomaticity is a possible reason for only two, and morphology is not relevant for the most frequent and semantically basic meanings that are encoded by lexical antonyms (e.g. big/ small, good/bad, high/low, thin/thick, wide/narrow, new/old, love/hate, rise/fall, and so forth).

4 This number includes both cases like good/bad or love/hate, as well as ones whose first member's positivity is not undisputable as it depends on the context, e.g. quickly/slowly, fast/ slow, active/passive or attack/defend.

5 Jones' list of antonyms was compiled following the researcher's intuition about what pairs are considered to be "good opposites" as well as the decision to include antonyms of different word classes, different antonym types (gradable and non-gradable adjectival pairs) and 
morphologically related pairs. Although certain pairs do appear in both this study and Jones' study, the antonym sample analyzed in these two studies is not identical. The choice of antonyms almost inevitably influences the results, and this will be dealt with in the Discussion section.

The Corpus of Contemporary American English (COCA) contains more than 450 million words of text and is equally divided among spoken, fiction, popular magazines, newspapers, and academic texts. It includes 20 million words each year from 1990-2012 and the corpus is also updated regularly (the most recent texts are from summer 2012).

In a total of all fifty-six pairs, 41 exhibit frequency asymmetries, which is around $73 \%$.

Cheap/expensive is influenced by the criterion of positivity because cheap is in all the examples in our database associated with a more favourable price, as opposed to expensive. Give/take is influenced by the criterion of positivity because give is in Coordinated Antonymy contexts in the database associated with being unselfish, as opposed to take.

\section{References}

Boucher, Jerry and Charles E. Osgood (1969) 'The Pollyanna hypothesis'. Journal of Verbal Learning and Verbal Behavior 8(1), 1-8.

Browman, Catherine and Louis M. Goldstein (1992) 'Articulatory phonology: An overview'. Phonetica 49, 155-180.

Charles, Walter G. and George A. Miller (1989) 'Contexts of antonymous adjectives'. Applied Psycholinguistics 10(3), 357-375.

Clark, Herbert H. (1970) 'Word associations and linguistic theory'. In: Lyons, John (ed.) New horizons in linguistics. Baltimore: Penguin, 271-286.

Clark, Herbert H. and Eve V. Clark (1978) 'Universals, relativity and language processing'. In: Greenberg, Joseph H., Charles A. Ferguson and Edith A. Moravcsik (eds.) Universals of human language (vol. 1). Stanford: Stanford University Press, 225-277.

Croft, William (2003) Typology and universals ( $2^{\text {nd }}$ edn.). Cambridge: Cambridge University Press.

Cruse, David A. (1986) Lexical semantics. Cambridge: Cambridge University Press.

Davies, Matt (2013) Oppositions and ideology in news discourse. London: Bloomsbury.

Deese, James (1964) 'The associative structure of some common English adjectives'. Journal of Verbal Learning and Verbal Behavior 3, 347-357.

Deese, James (1965) The structure of associations in language and thought. Baltimore: Johns Hopkins University Press.

Fellbaum, Christiane (1995) 'Co-occurrence and antonymy'. International Journal of Lexicography 8(4), 281-303.

Givón, Talmy (1970) 'Notes on the semantic structure of English adjectives'. Language 46, 816837.

Greenberg, Joseph H. (1966) Language universals, with special reference to feature hierarchies. The Hague: Mouton.

Hale, Kenneth L. (1971) ‘A note on a Warlpiri tradition of antonymy'. In: Steinberg, Danny D. and Leon A. Jakobovits (eds.) Semantics. An interdisciplinary reader in philosophy, linguistics and psychology. Cambridge: Cambridge University Press, 472-484.

Handke, Jurgen (1995) The structure of the lexicon: human versus machine. New York: Mouton de Gruyter.

Haspelmath, Martin (2006) 'Against markedness (and what to replace it with)'. Journal of Linguistics 42, 25-70.

Hsu, Chan Chia (2015) 'A syntagmatic analysis of antonym co-occurrences in Chinese: contrastive constructions and co-occurrence sequences'. Corpora 10(1), 47-82.

Jones, Steven (2002) Antonymy: A corpus-based perspective. London and New York: Routledge. 
Jones, Steven (2006) 'Antonym co-occurrence in spoken English'. Text and Talk 26(2), 191-216.

Jones, Steven (2007) “"Opposites" in discourse: A comparison of antonym use across four domains'. Journal of Pragmatics 39(6), 1105-1119.

Jones, Steven and M. Lynne Murphy (2005) 'Using corpora to investigate antonym acquisition'. International Journal of Corpus Linguistics 10(3), 401-422.

Justeson, John S. and Slava M. Katz (1991) 'Co-occurrences of antonymous adjectives and their contexts'. Computational linguistics 17, 1-19.

Justeson, John. S. and Slava M. Katz (1992) 'Redefining antonymy: the textual structure of a semantic relation'. Literary and Linguistic Computing 7, 176-184.

Karaman, Burcu I. (2008) 'On contronymy'. International Journal of Lexicography 21(2), 173192.

Kempson, Ruth M. (1977) Semantic theory. Cambridge: Cambridge University Press.

Kostić, Nataša (2011) 'Antonymous frameworks in Serbian written discourse: phrasal contexts of antonym co-occurrence in text'. Poznań Studies in Contemporary Linguistics 47(3), 509-537.

Kostić, Nataša (2015[a]) 'Antonymy in language use: from core members to ad hoc couplings'. Poznań Studies in Contemporary Linguistics 51(1), 133-161.

Kostić, Nataša (2015[b]) 'The textual profile of antonyms: a corpus-based study'. Linguistics 53(4), 649-675.

Leech, Geoffrey (1974) Semantics. Hardmonsworth: Penguin.

Leech, Geoffrey, Paul Rayson and Andrew Wilson (2001) Word frequencies in written and spoken English based on the British National Corpus. Harlow: Longman.

Lehrer, Adrienne (1985) 'Markedness and antonymy'. Journal of Linguistics 21(2), 397-429.

Lehrer, Adrienne (2002) 'Gradable antonymy and complementarity'. In: Cruse, David A., Franz Hundsnurscher, Michael Job and Peter R. Lutzeier (eds.) Handbook of lexicology. Berlin: de Gruyter, 498-506.

Lehrer, Adrienne and Keith Lehrer (1982) ‘Antonymy'. Linguistics and Philosophy 5(4), 483-501. Ljung, Magnus (1974) 'Some remarks on antonymy'. Language 50(1), 74-88.

Lobanova, Anna (2012) The anatomy of antonymy: A corpus-driven approach. The Netherlands: University of Gröningen dissertation.

Lobanova, Anna, Tom van der Kleij and Jennifer Spenader (2010) 'Defining antonymy: a corpusbased study of opposites by lexico-syntactic patterns'. International Journal of Lexicography 23(1), 19-53.

Lyons, John (1977) Semantics. Cambridge: Cambridge University Press.

Mayerthaler, Willi (1988) Naturalness in morphology. Ann Arbor: Karoma.

Mettinger, Arthur (1994) Aspects of semantic opposition in English. Oxford: Oxford University Press.

Moulton, Janice (1981) 'The debate over "he" and "man"'. In: Vetterling-Braggin, Mary (ed.) Sexist language. Totowa, NJ: Littlefield Adams, 100-115.

Mowrey, Richard and William Pagliuca (1995) 'The reductive character of articulatory evolution'. Rivista di linguistica 7(1), 37-124.

Muehleisen, Victoria and Maho Isono (2009) 'Antonymous adjectives in Japanese discourse'. Journal of Pragmatics 41(11), 2185-2203.

Murphy, Gregory L. and Jane M. Andrew (1993) 'The conceptual basis of antonymy and synonymy in adjectives'. Journal of Memory and Language 32(3), 301-319.

Murphy, M. Lynne (2000) 'Knowledge of words versus knowledge about words: the conceptual basis of lexical relations'. In: Peeters, Bert (ed.) The lexicon - encyclopedia interface. Amsterdam: Elsevier, 317-348.

Murphy, M. Lynne (2003) Semantic relations and the lexicon. Cambridge: Cambridge University Press.

Murphy, M. Lynne and Steven Jones (2008) 'Antonyms in children's and child-directed speech'. First Language 28(4), 403-430. 
Murphy, M. Lynne, Carita Paradis, Caroline Willners and Steven Jones (2009) 'Discourse functions of antonymy: a cross linguistic investigation of Swedish and English'. Journal of Pragmatics 41(11), 2159-2184.

Thurstone, Louis L. (1950) 'Some primary abilities in visual thinking'. Psychometric Laboratory Research Report 59. Chicago: University of Chicago Press.

Vendler, Zeno (1963) The transformational grammar of English adjectives. Pennsylvania: University of Pennsylvania, Department of Linguistics.

Waugh, Linda (1982) 'Marked and unmarked: a choice between unequals in semiotic structure'. Semiotica 38(3/4), 299-318.

Zwicky, Arnold (1978) 'On markedness in morphology'. Die Sprache 24, 129-143.

NataŠA Kostić is Associate Professor of English Morphology, Contrastive Analysis and General Linguistics at the Faculty of Philology, University of Montenegro. Dr Kostic graduated from the Faculty of Philology, University of Belgrade, where she also took her MA and PhD in Linguistics. She has published two books (Linguistic analysis of real conditional and Antonymy in discourse: a semanto-pragmatic analysis) and numerous articles in various scientific journals and monographs. Her fields of interest include syntax, cognitive semantics (conditionality and lexicalsemantic relations), pragmatics, contrastive analysis and the methodology of ELT.

Address: Prof. dr Nataša Kostić, Faculty of Philology, University of Montenegro, Jovana Tomaševića 37, Podgorica, Montenegro. [email: kostic@ac.me] 